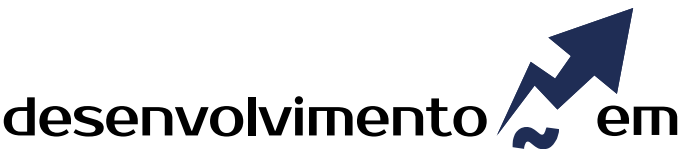 QUESTÃO
}

\section{Uma Revisão Crítica da Pesquisa Qualitativa em Gestão Territorial: Panorama da Produção Brasileira em Administração (2006-2015)}

\author{
http://dx.doi.org/10.21527/2237-6453.2019.46.112-129
}

Recebido em: 10/2/2017

Aceito em: 4/9/2018

\author{
José Raimundo Cordeiro Neto, ${ }^{1}$ Lizandra Kelly de Araújo Santana, ${ }^{2}$ \\ Nathália Arraes Guedes, ${ }^{3}$ André Luiz Maranhão de Souza Leão ${ }^{4}$
}

\begin{abstract}
RESUMO
O presente trabalho trata da produção científica brasileira da área de Administração e que utiliza abordagens qualitativas de investigação, no campo aqui denominado de gestão territorial. Apresenta-se uma pesquisa documental, simultaneamente bibliométrica e de revisão crítica, que analisou a mencionada produção a partir dos seguintes critérios: orientação paradigmática; lugar ocupado pela teoria no design de investigação; tradição de pesquisa utilizada; tipos de dados presentes; formas de análises desenvolvidas e critérios de qualidade adotados. A análise foi delimitada ao último decênio de publicações (2006-2015), sob a forma de artigos em periódicos nacionais, nos estratos de maior avaliação do Sistema Qualis/Capes, na área de Administração. Os achados indicam a predominância de perspectivas metodológicas construtivistas e que empregam recursos teóricos na condição de lente de auxílio à análise, sem enquadrar esta última em modelos teoricamente preconcebidos. Há elevada concentração das estratégias de pesquisa nos estudos de caso e prevalência da análise de conteúdo no tratamento dos dados, os quais, predominantemente, originam-se de documentos e entrevistas. É reduzida, nesse campo, a incorporação de critérios de qualidade em pesquisa qualitativa, destacando-se que em muitos trabalhos não se identifica o uso explícito de quaisquer deles e que em quase $40 \%$ não se esclarece sobre o caminho analítico tomado quanto ao material analisado. Ao final, este artigo discute possíveis implicações desses aspectos sobre o processo de produção de conhecimento em gestão territorial - considerando, especialmente, a configuração do campo em termos da natureza dos fenômenos investigados - e lança algumas considerações referentes ao aprimoramento e ampliação da pesquisa desenvolvida.
\end{abstract}

Palavras-chave: Pesquisa qualitativa. Gestão territorial. Análise bibliométrica. Revisão crítica.

\section{A CRITICAL REVIEW OF QUALITATIVE RESEARCH IN TERRITORIAL MANAGEMENT: BRAZILIAN PRODUCTION PANORAMA IN ADMINISTRATION (2006 -2015)}

\begin{abstract}
The present paper deals with the Brazilian scientific production of the area of Administration and that uses qualitative approaches of investigation, in the field here denominated by territorial management. We present a documentary, bibliometric and critical review research that analyzed this production, based on the following criteria: paradigmatic orientation; Place occupied by theory in research design; Tradition of research used; Types of data present; Forms of analysis developed; And quality criteria adopted. The analysis was delimited in the last decade of publications (2006-2015), in the form of articles in Brazilian journals, in the strata of higher evaluation of the Qualis/Capes System, in the Administration area. The findings indicate the predominance of constructivist methodological perspectives and that employ theoretical resources as an aid to analysis, without placing the latter in theoretically preconceived models. There is a high concentration of research strategies in the case studies and prevalence of content analysis in data analysis, which predominantly originate from documents and interviews. In this field, the incorporation of quality criteria into qualitative research is reduced, and in many studies the explicit use of any of them is not identified and in almost $40 \%$ it is not clarified about the analytical path taken in relation to the material analysed. In the end, this paper discusses possible implications of these aspects on the process of knowledge production in territorial management - especially considering the field configuration in terms of the nature of the investigated phenomena - and makes some considerations regarding the improvement and expansion of the research developed.
\end{abstract}

Keywords: Qualitative research. Territorial management. Bibliometric analysis. Critical review.

\footnotetext{
${ }^{1}$ Mestre em Administração e aluno de Doutorado pelo Programa de Pós-Graduação em Administração da Universidade Federal de Pernambuco (Ufpe).cordeironneto@gmail.com

${ }^{2}$ Mestre em Administração pelo Programa de Pós-Graduação em Administração da Universidade Federal de Pernambuco (Ufpe). lizandraaraujo.adm@gmail.com

${ }^{3}$ Graduada em Administração e aluna de Mestrado pelo Programa de Pós-Graduação em Administração da Universidade Federal de Pernambuco (Ufpe). nathaliarraes@gmail.com

${ }^{4}$ Doutor em Administração pelo Programa de Pós-Graduação em Administração da Universidade Federal de Pernambuco (Ufpe). Professor do Programa de Pós-Graduação em Administração da Universidade Federal de Pernambuco (Ufpe). aleao21@hotmail.com
} 
As Ciências Sociais têm assistido, desde o final do século 20, um crescente interesse sobre aspectos relacionados à territorialidade. Isso pode ser constatado na literatura de diversos campos de conhecimento, como a Sociologia, a Geografia, a Economia e a Administração. Trata-se de perspectivas para além da discussão das questões espaciais tradicionalmente abordadas pela economia regional e urbana (BRANDÃO, 2007a; CUNHA; SIMÕES; PAULA, 2005). Nelas, incorporam-se novas concepções sobre território e territorialidade (HAESBAERT, 2012), ultrapassando compreensões mais restritas do que seja a dimensão geográfica, para contemplar elementos diversos, de questões técnico-científicas (CASTELLS, 2006; SANTOS, 2008) a dinâmicas de poder, processos culturais e institucionais (CASTELLS, 1999; BOURDIEU, 2006; BOISIER, 1995; ABRAMOVAY, 2006), bem como as conexões entre essas dimensões.

As repercussões desse renovado interesse sobre a territorialidade parecem manifestar-se diferentemente nos distintos campos disciplinares. Na área das pesquisas em Administração, por exemplo, tal interesse tem se traduzido em abordagens de investigação e discussão em torno do que se poderia denominar de "gestão territorial". Com essa denominação pretende-se, aqui, referir-se a um amplo conjunto de trabalhos caracterizados por abordarem aspectos da gestão em sua dimensão territorial. Isto é, são estudos que tratam de questões e processos mais amplos que aqueles costumeiramente localizados em fronteiras organizacionais específicas, privilegiando a análise de elementos referentes ao território (empírica ou teoricamente situado), geralmente entendidos de modo intimamente associado às temáticas gerenciais e organizacionais.

No Brasil, algumas perspectivas parecem ilustrativas desse conjunto, tais como as discussões sobre a gestão territorial do desenvolvimento, presentes nas proposições de autores como Fischer (2002), Tenório $(1998,2008)$ e Goulart et al. (2010); e os trabaIhos voltados para a ideia de governança territorial, identificada em autores como Dallabrida (2010, 2015), Vieira e Vieira (2007) e Andion (2003, 2006). Seria forçoso afirmar a existência de absoluta convergência entre as diferentes abordagens no interior dessas perspectivas, porém, não obstante as distinções no interior desse campo de estudos, o interesse do presente trabalho recai sobre o conjunto dessas abordagens, em sua totalidade.

Especialmente, diante da recente emergência desses estudos, pretende-se identificar elementos que os caracterizem, panoramicamente, em termos de estratégias de investigação utilizadas. Para essa ênfase nas questões metodológicas dos estudos sobre gestão territorial, contribui a compreensão de que o caráter emergente dessa perspectiva no campo da Administração torna oportuna a discussão sobre quais opções têm sido predominantemente feitas na área, quando da necessidade de se abordar seu objeto de estudo. Além disso, este trabalho voltou-se especificamente para as pesquisas que declaram utilizar "abordagens qualitativas", visto que esta tradição abre, em tese, maior espaço para esforços indutivos e novas formas de tratamento teórico-empírico, em especial em áreas nas quais os esforços de teorização estão em desenvolvimento e nas quais, principalmente, a natureza dos problemas discutidos parece menos afeita às posturas de pesquisa que incluam a mensuração como forma privilegiada de compreensão dos fenômenos. 
Com isso, o presente trabalho apresenta uma pesquisa documental que buscou analisar a produção científica nacional em Gestão Territorial, na área de Administração, enfatizando as produções compreendidas como abordagens qualitativas da temática. Essa opção de delimitação decorre da priorização em analisar trabalhos no campo em que os autores e autoras do presente artigo estão mais imediatamente inseridos em suas contribuições acadêmicas, além do entendimento de que abordagens em Gestão Territorial têm apresentado destaque na área de Administração e mostram-se relativamente incipientes no Brasil.

De um lado, a referida produção foi analisada bibliometricamente, com o intuito de revelar elementos que se sobressaem no campo estudado e, de outro, procedeu-se a um escrutínio reflexivo quanto ao emprego da tradição de pesquisa qualitativa nesse campo, o que permitiu uma discussão sobre questões de qualidade e acurácia implicadas nas opções metodológicas, presentes nos trabalhos analisados. Tal apreciação, vale ressaltar, oportunizou que a análise considerasse importantes debates que a tradição qualitativa de pesquisa tem consolidado ao longo de seu desenvolvimento (CRESWELL, 2010; DEZIN; LINCOLN, 2006; GODOI; BANDEIRA-DE-MELLO, 2007) como modo particular de investigação.

A seguir, em seção específica, são realçadas algumas perspectivas teóricas presentes no que se está denominando de gestão territorial, a fim de tornar mais claros os contornos do campo abordado. Na sequência apresentam-se os procedimentos que foram adotados para operacionalizar a análise realizada. Uma terceira seção mostra os resultados e discussões. Por fim, considerações mais gerais são tecidas, buscando refletir sobre os achados da pesquisa e suas implicações para o campo temático aqui abordado.

\section{PERSPECTIVAS TEÓRICAS EM TORNO DA NOÇÃO DE GESTÃO TERRITORIAL}

As abordagens teóricas que se ocupam das intersecções entre os conceitos de gestão e território têm uma proximidade analítica com a renovação do interesse acadêmico, nas últimas décadas do século 20 , sobre as particularidades locais de processos mais amplos, especialmente no que respeita ao fenômeno denominado de desenvolvimento e, neste, às variantes adjetivadas como desenvolvimento social e desenvolvimento econômico.

Questões relacionadas à dimensão especial dos processos socioeconômicos têm sido, de longa data, tratadas em disciplinas como a Economia Regional e a Geografia Econômica, sobretudo em termos da análise da desigual distribuição da atividade produtiva - e suas implicações - entre nações e no interior destas (BOISIER, 1996; CUNHA; SIMÕES; PAULA, 2005). O renovado interesse sobre as condições locais do desenvolvimento, todavia, passou a compreender preocupações para além das abordagens tradicionais daquelas disciplinas, distanciando-se notadamente do escopo da economia clássica (MULS, 2008; BRANDÃO, 2007a).

Emergiram, assim, novas perspectivas de estudos com vistas à compreensão da dimensão local do desenvolvimento, contemplando, por exemplo, o papel das instituições e do percurso histórico-cultural das localidades em suas trajetórias de desenvolvimento (ABRAMOVAY, 2000, 2006; DINIZ; LEMOS, 2005; MULS, 2008). Nesse direcionamento, a ideia de local já não guarda uma identificação com a noção convencional de região, esta 
costumeiramente compreendida como delimitação espacial a partir de variáveis econômicas, demográficas ou de divisões governamentais. Numa ênfase sobre as peculiaridades das relações que diferentes atores e grupos imprimem às dinâmicas locais, seja em suas interações em si, seja nos vínculos estabelecidos com atores e grupos externos, a noção de local passa a ser mais próxima da ideia de território (BRANDÃO, 2007a; ABRAMOVAY, 2006).

Como decorrência, o reconhecimento da enorme diversidade de contextos territoriais e de suas trajetórias, por sua vez, passa a implicar a inocuidade de diretrizes padronizadas nas recomendações políticas que visam ao desenvolvimento desses contextos (MULS, 2008; EVANS, 2003). Tal desenvolvimento, nesse sentido, não seria possível por meio do que Evans (2003) chama de monocultura institucional, isto é, de receituários que desconsiderem as singularidades envolvidas. Qualquer esforço de mudança nas condições socioeconômicas em dado território exigiria a consideração prévia de suas dinâmicas locais específicas. Além disso, tal mudança, nessa perspectiva, não decorreria de processos espontâneos de correção de desigualdades via autorregulação dos mercados, mas sim da capacidade dos distintos atores envolvidos em promoverem, conjuntamente, as transformações localmente desejadas (FISCHER, 2002; ABRAMOVAY, 2006).

O processo de desenvolvimento, nesta abordagem, é tomado a partir de bases essencialmente territoriais. E seu desencadeamento e fluidez requerem um tipo específico de governança, compreendido especialmente em termos do planejamento e da gestão necessárias às mudanças territoriais almejadas em determinado contexto (DALLABRIDA, 2010, 2015; MULS, 2008; FISCHER, 2002). Conforme Dallabrida (2015), esse processo está centrado nas articulações dos atores envolvidos em torno de uma estratégia de mudança, por meio de redes de poder socioterritoriais, o que pressupõe algum pacto sobre os rumos pretendidos e alguma visão de futuro compartilhada por eles.

Em tais redes de articulação - presumidas pela ideia de gestão das dinâmicas territoriais - é assumida, como condição básica, a presença da diversidade de atores locais, e mesmo extralocais, implicados nos processos de mudança almejados. Nesse ponto deve-se esclarecer que tal pressuposto não significa a aceitação tácita de uma visão idílica sobre os territórios. Pelo contrário, incorpora-se a crítica à ideia de localidades como cenários pacíficos de homogeneidade de interesses e de visões de mundo (OLIVEIRA, 2001), considerando necessariamente as heterogeneidades, os conflitos e a difícil emergência de consensos em territórios que, tal como a sociedade em geral, também são constituídos de grupos com interesses por vezes antagônicos (BRANDÃO, 2007a, 2007b; FISCHER, 2002).

Assim, o tipo de pacto ou de concertação social, presentes na perspectiva da Gestão Territorial, é assumido na condição de resultante de processos complexos de negociação e de compartilhamento de estratégias em ambientes plurais de interação, nos quais atores e suas organizações não estão associados por meio de cadeias rígidas de poder hierárquico, o que exige lidar com diferentes graus de autonomia e de envolvimento entre os participantes (FISCHER, 2002). Em tais cenários, os pactos e estratégias coletivos não se fundariam em amplos e definitivos consensos (BRANDÃO, 2007b), mas sim em acordos razoavelmente estáveis e catalisadores de engajamento, embora sem- 
pre sujeitos a rearranjos e rupturas, nunca espontâneos, mas conduzidos como parte dos esforços de governança local (DALLABRIDA, 2010, 2015; ABRAMOVAY, 2006; FISCHER, 2002).

No conjunto de atores envolvidos nas dinâmicas territoriais, embora essa perspectiva de estudos não privilegie, em sua análise, o papel do Estado e dos agentes governamentais, tampouco se admite a defesa da ausência destes últimos em nome de uma pretensa autossuficiência da parte da sociedade que se convencionou denominar de segundo e terceiro setores (DALLABRIDA, 2010, 2015; FISCHER, 2002; MULS, 2008). Tal abordagem compreende que as estratégias de desenvolvimento dos territórios precisam tomar forma em ambientes de deliberação democrática, entendidos a partir da ideia de espaço público ampliado (TENÓRIO, 2008), o qual transcende a delimitação de setor público como domínio estatal e incorpora a diversidade de atores implicados - inclusive o Estado - nas questões coletivas a serem enfrentadas.

Essas perspectivas, em síntese, estão amplamente presentes nos estudos que tratam da inter-relação entre gestão e território e, embora não seja pretensão do presente trabalho esmiuçar como essas ideias são tomadas no âmbito dos artigos analisados, elas são esclarecedoras quanto ao escopo da temática abordada.

\section{PROCEDIMENTOS METODOLÓGICOS}

Para operacionalizar a pesquisa ora apresentada, algumas escolhas metodológicas foram tomadas, no intuito de viabilizar o trabalho realizado. Tais escolhas referem-se, especialmente, ao escopo da produção científica analisada e aos aspectos que foram privilegiados no estudo.

\section{O Escopo da Produção Analisada}

Em primeiro lugar, optou-se por delimitar a análise ao período do último decênio de publicações científicas (2006-2015), sob a forma de artigos veiculados por periódicos nacionais da área de Administração. Compreende-se que este recorte temporal incorpora o processo de amadurecimento mais recente do campo e que a opção pelos periódicos permite acessar apenas trabalhos que refletem pesquisas em estágio mais avançado do que se obteria com o acesso à produção divulgada por meio de encontros de pesquisadores, por exemplo.

Para a delimitação operacional da área de Administração, utilizou-se a convencional classificação de áreas de conhecimento e de avaliação de periódicos (Sistema Qualis/Capes), realizada pela Coordenação de Aperfeiçoamento de Pessoal do Ensino Superior, do Ministério da Educação (Capes/MEC). A pesquisa concentrou-se nos estratos mais elevados de classificação dos periódicos (A1 e A2), os quais, em tese, refletem os canais de publicação com maior expertise no cenário nacional, sugerindo que os artigos ali publicados compreendem resultados de pesquisas significativamente amadurecidas. Para a área de Administração, por não haver nenhum periódico nacional classificado no estrato $A 1$, a pesquisa deteve-se no estrato seguinte, no qual foram identificados oito periódicos. 
Nos periódicos identificados realizou-se a busca de artigos que contemplassem a temática "Gestão Territorial" nas edições compreendidas no decênio 2006-2015. Essa busca foi realizada a partir de um conjunto predefinido de palavras-chave, por meio do Sistema Eletrônico de Editoração de Revistas (Seer) - ou manualmente edição por edição (quando o Seer não estava disponível para um ou outro periódico específico). Das oito revistas do estrato $A 2$, as produções coletadas para posterior análise foram encontradas nas seis seguintes: Revista de Administração Pública - RAP (50 artigos); Revista Organizações \& Sociedade - O\&S (36 artigos); Cadernos Ebape - CEBAPE.BR (29 artigos); Revista de Administração da USP - Rausp (19 artigos); Revista de Administração Contemporânea - RAC (10 artigos); e Revista de Administração de Empresas - RAE (2 artigos). Essa coleta inicial permitiu, por conseguinte, formar um arquivo compreendendo 146 artigos, dos quais 40 foram eliminados numa primeira revisão $(27,97 \%)$, pelo critério de não adesão à área temática, isto é, por não contemplarem a categoria território como elemento relevante para as discussões neles realizadas, apesar de associados a uma ou mais das palavras-chave utilizadas na busca.

$\mathrm{Na}$ etapa seguinte procedeu-se à exclusão dos ensaios teóricos, dos artigos resultantes de pesquisa quantitativa e daqueles que fizeram uso de métodos mistos. Com isso, o conjunto de documentos foi reduzido em $54,1 \%$ do total inicial, resultando num agrupamento final de 79 artigos, que empregam apenas abordagem qualitativa - foco do presente trabalho, como referido na seção introdutória. É válido realçar o fato de que apenas $10,27 \%$ do agrupamento inicial era composto por trabalhos que recorreram exclusivamente à abordagem quantitativa, percentual esse que reforça o argumento pela ênfase da análise sobre o emprego de recursos qualitativos de investigação nesse campo. Uma vez aplicados os filtros mencionados, o próximo passo foi o tratamento analítico desses artigos reunidos, o que se explicitará na próxima subseção.

\section{Os Aspectos Privilegiados na Análise e Procedimentos Analíticos}

Num segundo conjunto de escolhas metodológicas, tomadas nesta pesquisa, os 79 artigos, que permaneceram no arquivo a ser estudado, foram analisados segundo os aspectos listados no Quadro 1, a seguir. Os aspectos elencados foram considerados com a finalidade de proporcionar uma adequada apreciação da produção abordada, pois dizem respeito aos principais pontos envolvidos num plano de pesquisa qualitativa, propiciando que se avalie a qualidade e acurácia de cada artigo, em termos dos procedimentos metodológicos neles empregados.

Quadro 1 - Aspectos privilegiados na análise

\begin{tabular}{|l|l|}
\hline \multicolumn{1}{|c|}{ Aspectos } & \multicolumn{1}{c|}{ Descrição } \\
\hline $\begin{array}{l}\text { Orientação } \\
\text { paradigmática }\end{array}$ & $\begin{array}{l}\text { Por orientação paradigmática compreende-se a postura epistemológica à qual cada } \\
\text { trabalho se vincula, tomando-se a classificação de Lincoln e Guba (2006), entre } \\
\text { positivismo; pós-positivismo; construtivismo; teoria crítica e outras. }\end{array}$ \\
\hline $\begin{array}{l}\text { O lugar da } \\
\text { teoria }\end{array}$ & $\begin{array}{l}\text { Quanto ao lugar da teoria, optou-se por adotar a sistematização discutida por Leão, } \\
\text { Mello e Vieira (2009), quando apresentam um continuum entre a abordagem } \\
\text { hipotético-dedutiva e a indutiva, passando pela ideia de duplo pensamento reflexivo; } \\
\text { modelo de construto e uso de uma teoria geral. }\end{array}$ \\
\hline
\end{tabular}




\begin{tabular}{|c|c|}
\hline $\begin{array}{l}\text { Tradição da } \\
\text { pesquisa }\end{array}$ & $\begin{array}{l}\text { Em relação à tradição de pesquisa, foram consideradas as principais estratégias } \\
\text { discutidas por Creswell (2010), sendo as mais frequentes: o estudo de caso, pesquisa } \\
\text { narrativa, fenomenologia, etnografia e ground theory. }\end{array}$ \\
\hline $\begin{array}{l}\text { Tipo de dados } \\
\text { utilizados }\end{array}$ & $\begin{array}{l}\text { Para abordar os tipos de dados utilizados, a pesquisa preocupou-se em classificar } \\
\text { a produção analisada quanto à fonte de seus dados, o que também permite } \\
\text { compreender a natureza deles, a partir, por exemplo, de sua origem em entrevistas, } \\
\text { fontes documentais ou observação, para citar algumas. }\end{array}$ \\
\hline $\begin{array}{l}\text { Tipo de } \\
\text { análises } \\
\text { realizadas }\end{array}$ & $\begin{array}{l}\text { Em relação ao tipo de análise realizada, este trabalho tomou a perspectiva de agrupar } \\
\text { o material conforme o tratamento analítico empreendido: da clássica análise de } \\
\text { conteúdo, até perspectivas como a análise do discurso, de narrativas, entre outras. }\end{array}$ \\
\hline $\begin{array}{l}\text { Critérios de } \\
\text { qualidade } \\
\text { presentes }\end{array}$ & $\begin{array}{l}\text { Por fim, critérios de qualidade foram observados em cada produção, seguindo-se a } \\
\text { orientação presente no trabalho de Paiva Jr., Leão e Mello (2011), quando destacam } \\
\text { os principais tipos de recursos pelos quais se busca assegurar qualidade em pesquisa } \\
\text { qualitativa. }\end{array}$ \\
\hline
\end{tabular}

Fonte: Elaborado pelos autores, 2016.

Vale ressaltar que, como mencionado anteriormente, nesta etapa do estudo o artigo permaneceu como a unidade de análise, com cada um dos 79 trabalhos reunidos sendo classificado individualmente, para cada um dos seis aspectos listados. Tais classificações foram realizadas, separadamente, por cada um dos autores deste trabalho, e foram posteriormente contrastadas, a fim de que eventuais divergências fossem debatidas. Isso permitiu revisitar artigos e proceder a eventuais reclassificações, sempre que julgado necessário, o que se deu, efetivamente, em 12 das classificações prévias.

Em seguida, os dados resultantes foram organizados a partir da utilização de ferramentas de estatística descritiva, obtendo-se informações mais sistematizadas sobre a presença daqueles aspectos do Quadro 1, no conjunto dos trabalhos, o que permitiu a apresentação e discussão dos resultados trazidos na próxima seção.

\section{PANORAMA DA PESQUISA QUALITATIVA NO CAMPO DA GESTÃO TERRITORIAL: Resultados e Discussões Sobre a Produção Brasileira da Área de Administração}

A seguir, os aspectos privilegiados na análise realizada são apresentados e discutidos. A análise bibliométrica está, desse modo, acompanhada das considerações referentes à revisão crítica, tecida para cada ponto.

\section{Orientação Paradigmática: a dominância de abordagens construtivistas}

Quanto às questões paradigmáticas que orientam o campo dos estudos apreciados, compreendidas como aquelas relacionadas às posturas epistemológicas tomadas nos processos de pesquisa realizados, a análise revelou uma elevada predominância da perspectiva denominada por construtivismo (Tabela 1). 


\section{TABELA 1 - ORIENTAÇÃO PARADIGMÁTICA NOS ESTUDOS ANALISADOS}

\begin{tabular}{|c|c|c|c|c|c|c|c|c|}
\hline Paradigma & O\&S & RAP & CEBAPE.BR & RAC & RAE & RAUSP & TOTAL & \% \\
\hline Positivismo ou & & & & & & & & \\
pós-positivismo & 8 & 7 & 0 & 1 & 0 & 0 & 16 & 20,25 \\
Construtivismo & 9 & 25 & 20 & 1 & 1 & 5 & 61 & 77,22 \\
Teoria Crítica & 1 & - & 1 & - & - & - & 2 & 2,53 \\
\hline TOTAL & $\mathbf{1 8}$ & $\mathbf{3 2}$ & $\mathbf{2 1}$ & $\mathbf{2}$ & $\mathbf{1}$ & $\mathbf{5}$ & $\mathbf{7 9}$ & $\mathbf{1 0 0}$ \\
\hline
\end{tabular}

Fonte:. Elaborada pelos autores.

Como observado na Tabela 1 , apenas $1 / 5$ dos artigos $(20,25 \%)$ se alinha a uma compreensão do próprio fazer científico como um processo de descoberta de verdades objetivistas (positivismo ou pós-positivismo), que estariam sujeitas a métodos de verificação ou de falseabilidade. A grande maioria $(77,22 \%)$ insere-se numa perspectiva epistemológica construtivista, se considerarmos tal perspectiva como aquela que compreende o conhecimento produzido como uma construção transacional e subjetivista, fortemente associado às formas específicas de interação entre o pesquisador e o objeto de seu interesse. Tal postura está, assim, associada ao relativismo, à concepção de que as realidades são locais e construídas em planos específicos. Evidenciou-se, ainda, que é inexpressiva a produção $(2,53 \%)$ vinculada à abordagem crítica ou perspectivas semelhantes, assim entendidas como aquelas que privilegiem a perspectiva histórica de construção da realidade, por meio de valores temporalmente sedimentados pela vida em sociedade, no sentido utilizado por autores como Lincoln e Guba (2006).

Deve-se considerar, conforme Reckwitz (2002) assinala, que o termo construtivismo - ou, por vezes, interpretativismo - pode constituir uma nomenclatura muito vaga para agrupar uma variedade considerável de abordagens ditas culturais, ainda que estas mantenham notáveis distinções entre elas. Ainda assim, pode-se afirmar que a elevada representatividade de estudos dessa natureza, no âmbito das pesquisas brasileiras em Gestão Territorial, é um indicador de que, muito provavelmente, esse campo tenderá a manter uma significativa diversidade de formas de abordagem. Isso porque o paradigma construtivista, ao contrário do positivismo e suas variantes, não assume como desejável conduzir a produção científica a um estágio de "ciência normal", em que determinada forma de teorização possa ser aceita como modus operandi da comunidade de pesquisadores.

\section{O Lugar da Teoria: \\ significativa distância dos extremos da dedução e da indução}

No que diz respeito ao lugar da teoria na produção científica analisada, evidenciou-se que poucos dos trabalhos reunidos se caracterizam pelos extremos da dedução $(7,59 \%)$ ou da indução puras $(0,0 \%)$, como se pode verificar na Tabela 2 , a seguir. Ou seja, é pouco frequente o emprego de teorias como recurso para a operacionalização dos estudos, precondicionando a análise dos dados ao uso de um conjunto de variáveis hierarquizadas por alguma elaboração teórica, antecipadamente tomada como dada. E, 
por outro lado, não foi observada a presença de trabalhos em que inexistisse qualquer orientação teórica preliminar ao esforço de analisar os dados, o que consistiria na abordagem completamente indutiva.

Tabela 2 - Posicionamento da teoria nos estudos analisados

\begin{tabular}{ccccccccc}
\hline Posicionamento da teoria & O\&S & RAP & CEBAPE.BR & RAC & RAE & Rausp & Total & $\%$ \\
Hipotético-dedutivo & 3 & 3 & - & - & - & - & 6 & 7,59 \\
Indutivo puro & - & - & - & - & - & - & - & 0 \\
Duplo pensamento reflexivo & - & 2 & - & - & - & - & 2 & 2,53 \\
Modelo de construto & 1 & 9 & 4 & 1 & 1 & 2 & 18 & 22,78 \\
Teoria Geral & 14 & 18 & 17 & 1 & 0 & 3 & 53 & 67,09 \\
\hline Total & $\mathbf{1 8}$ & $\mathbf{3 2}$ & $\mathbf{2 1}$ & $\mathbf{2}$ & $\mathbf{1}$ & $\mathbf{5}$ & $\mathbf{7 9}$ & $\mathbf{1 0 0}$ \\
\hline
\end{tabular}

Fonte: Elaborada pelos autores.

Nota-se, conforme a tabela apresentada anteriormente, que perspectivas intermediárias, no continuum dedução-indução, mostraram-se predominantes, com destaque para investigações que tomam determinadas formulações teóricas, como orientação geral, para o desenvolvimento de suas análises, porém sem chegar a constituir um modelo conceitual de variáveis predeterminadas na operacionalização dos esforços analíticos. Significa afirmar que é mais recorrente a adoção daquilo que se pode chamar de teoria geral $(67,09 \%$ ou pouco mais de $2 / 3)$, no sentido expresso por Leão, Mello e Vieira (2009). Ademais, o uso de perspectivas teóricas em um sentido mais operacional para a análise, porém ainda com alguma margem para a indução, aparece em $22,78 \%$ dos trabalhos, os quais podem ser classificados como adotantes da perspectiva de construto, isto é, que empregam algum modelo analítico prévio, mas resguardam a possibilidade de que elementos novos possam emergir durante o estudo.

É notório que, mesmo pesquisas de orientação (pós)positivista, em boa medida, evitam localizar-se na dedução extrema, o que se pode observar cruzando as informações da tabela desta subseção com as apresentadas na subseção anterior. Dito de outra forma, nem todos os $20,25 \%$ dos trabalhos que apresentam uma postura epistemológica alinhada ao positivismo recorrem ao emprego de modelos hipotético-dedutivos de análise. Ademais, um cruzamento de dados dessa mesma natureza (entre as Tabelas 1 e 2) permite visualizar o alinhamento entre a dominância de posturas epistemológicas construtivistas com formas de investigação relativamente abertas à compreensão de particularidades contextuais (abertura à indução).

Ainda cabe destacar que a configuração do campo da Gestão Territorial, no que diz respeito a esse elemento, de posicionamento da teoria no design de pesquisa, parece condizente com uma área cuja emergência é relativamente recente e cujo processo de formulação de teorias encontra-se em desenvolvimento. Com isso não se quer afirmar que os pesquisadores do campo necessariamente caminharão para uma tendência à adoção de desenhos menos indutivos conforme o campo amadureça seu debate, mas que, em razão do seu incipiente processo de teorização, parece razoável que a área não estabeleça, em seus projetos de investigação, fundamentações teóricas dadas de antemão como determinantes das leituras empíricas. 


\section{Tradição de Pesquisa: a elevada frequência dos estudos de caso}

Do conjunto de artigos analisados, pouco (18,99\%) se refere a pesquisas que tenham lançado mão de outra tradição investigativa que não seja o estudo de caso qualitativo, como se pode visualizar na Tabela 3, apresentada a seguir. Nos $81,01 \%$ restantes, a presente análise agrupou tanto aqueles estudos que declararam o emprego do estudo de caso quanto aqueles que, mesmo sem fazê-lo, apresentavam um design de pesquisa em que predominavam características daquela tradição.

Tabela 3 - Tradição de pesquisa nos estudos analisados

\begin{tabular}{|c|c|c|c|c|c|c|c|c|}
\hline $\begin{array}{l}\text { Tradições de } \\
\text { Pesquisa }\end{array}$ & O\&S & RAP & CEBAPE.BR & RAC & RAE & Rausp & Total & $\%$ \\
\hline Estudo de Caso & 14 & 26 & 17 & 2 & - & 5 & 64 & 81,01 \\
\hline Etnografia & - & - & - & - & - & - & 0 & 0,00 \\
\hline Fenomenologia & - & - & - & - & - & - & 0 & 0,00 \\
\hline Grounded Theory & - & 1 & - & - & 1 & - & 2 & 2,53 \\
\hline Narrativa & 1 & - & 2 & - & - & - & 3 & 3,80 \\
\hline Outros & 2 & 1 & 1 & - & - & - & 4 & 5,06 \\
\hline Não Identificada & 1 & 4 & 1 & - & - & - & 6 & 7,59 \\
\hline Total & 18 & 32 & 21 & 2 & 1 & 5 & 79 & 100 \\
\hline
\end{tabular}

Fonte: Elaborada pelos autores.

Ao lado da supremacia do estudo de caso observa-se, ainda nos dados trazidos pela Tabela 3, uma incipiente utilização de tradições como a pesquisa narrativa $(3,80 \%)$ e a grounded theory (2,53\%), mas também uma ausência de trabalhos orientados pelas tradições da fenomenologia e da pesquisa etnográfica.

Essa predominância do estudo de caso, aqui evidenciada no campo da Gestão Territorial, também já fora verificada em outros campos da área de Administração, a exemplo dos estudos organizacionais, como destacaram Mariz et al (2005). Os autores também revelaram, ali, imprecisões e fragilidades significativas do uso dessa tradição de pesquisa. Assim, por um lado, é possível afirmar que o estudo de caso consiste numa estratégia de pesquisa condizente com a investigação de processos sociais intrinsecamente contextuais, como os assumidos pelos estudos em Gestão Territorial, permitindo certa diversificação no recurso a distintas fontes de dados, para a compreensão das particularidades das experiências estudadas e seus significados para os atores envolvidos. Por outro lado, pode-se questionar em que medida esse predomínio do estudo de caso entre os trabalhos analisados revela apenas uma tendência, da área de Administração como um todo, e menos um alinhamento com a natureza do campo específico aqui abordado.

Discussão semelhante poderia envolver, ainda, a ausência das orientações etnográficas e fenomenológicas, mesmo quando as questões de natureza cultural, centrais na etnografia, parecem tão relevantes para a compreensão de processos territoriais, como parte da própria literatura em Gestão Territorial aponta. Por sua vez, ainda que as particularidades de fenômenos específicos (questão basilar na fenomenologia) sejam 
elementos de destaque no entendimento de dinâmicas vividas em territórios, procedimentos de pesquisa fenomenológica parecem exercer pouca atratividade no âmbito dos trabalhos sob análise.

\section{Tipos de Dados: o uso intenso de fontes documentais e de entrevistas}

Documentos (presentes em $42,45 \%$ dos artigos), entrevistas (em 38,13\%) e observações (em 17,27\%) são, nessa ordem, as três principais fontes dos dados coletados e analisados nos estudos sobre Gestão Territorial, conforme detalhado na Tabela 4, que consta a seguir. Registre-se, também, que a maior parte dos artigos emprega mais de um tipo de dados, motivo pelo qual a frequência absoluta acumulada na Tabela 4 é maior que o número total de 79 artigos analisados.

Tabela 4 - Tipos de dados coletados nos estudos analisados

\begin{tabular}{lcccccccc}
\hline $\begin{array}{c}\text { Tipos de Dados } \\
\text { Coletados }\end{array}$ & O\&S & RAP & CEBAPE.BR & RAC & RAE & RAUSP & Total & $\%$ \\
\hline Fonte Documental & 12 & 29 & 15 & 2 & 1 & 3 & 59 & 42,45 \\
\hline Entrevista & 10 & 22 & 19 & 1 & 1 & 5 & 53 & 38,13 \\
Observação & 3 & 9 & 11 & 1 & - & 2 & 24 & 17,27 \\
Focus Group & - & 1 & - & - & - & - & 1 & 0,72 \\
Não identificado & - & 1 & 1 & - & - & - & 2 & 1,44 \\
\hline Total & $\mathbf{2 5}$ & $\mathbf{6 2}$ & $\mathbf{4 6}$ & $\mathbf{4}$ & $\mathbf{2}$ & $\mathbf{1 0}$ & $\mathbf{1 3 9}$ & $\mathbf{1 0 0}$ \\
\hline
\end{tabular}

Fonte: Elaborada pelos autores.

Aqui, pode-se questionar sobre a elevada presença dos dados documentais no campo dos estudos sobre Gestão Territorial, mesmo quando o costumeiro na área de Administração é que predominem os dados oriundos de entrevistas - não obstante esses últimos também sejam significativos nos trabalhos ora analisados (38,13\%). Talvez o uso intensivo de documentos nesse campo esteja associado à proximidade de áreas como a Administração Pública ou ao fato de que muitas dinâmicas territoriais possam ter sua compreensão facilitada pela disponibilidade de registros formais, presentes em organizações públicas ou privadas envolvidas nos processos estudados. Também pode-se indagar em que medida isso atribuiria ao campo algum diferencial em termos de oportunidades de triangulação de dados, vis-à-vis outros campos de pesquisa menos favorecidos com a presença de dados secundários.

\section{Tipos de Análises:}

\section{a ênfase na análise de conteúdo e indefinições analíticas}

Neste aspecto da pesquisa decidiu-se preservar, sempre que possível, a nomenclatura dada pelos próprios autores quanto à técnica de análise realizada. Ainda assim, para cada artigo buscou-se verificar se a técnica declarada pelos autores era condizente com os procedimentos descritos na seção referente às questões metodológicas e com aquilo que constava na seção de discussão e análise dos resultados.

Majoritariamente, conforme apresentado na Tabela 5 (a seguir), percebe-se que a Análise de Conteúdo (AC), sistematizada em Bardin (1977), constitui a técnica mais utilizada na produção analisada (presente em 40,50\% dos artigos), seja pela sua conso- 
lidação metodológica, facilidade de operacionalização ou até mesmo por familiaridade dos autores. Significativas fragilidades, entretanto, foram encontradas no emprego da AC nesse conjunto de trabalhos, a exemplo do reduzido diálogo entre as discussões teóricas desenvolvidas nos artigos e a operacionalização de categorias analíticas utilizadas quando do tratamento dos dados.

Por sua vez, a utilização da Análise do Discurso (AD) - que guarda significativo distanciamento da AC por considerar a linguagem em termos mais amplos que os elementos textuais estritos (expressões orais ou não, a exemplo dos não ditos) - foi utilizada em apenas 10,13\% da produção apreciada.

Tabela 5 - Tipos de análises realizadas nos estudos analisados

\begin{tabular}{lcccccccc}
\hline \multicolumn{1}{c}{ Tipos de Análises } & O\&S & RAP & CEBAPE.BR & RAC & RAE & Rausp & Total & $\%$ \\
Análise de Conteúdo & 9 & 14 & 4 & 1 & 1 & 3 & 32 & 40,50 \\
Analise de Discurso & 1 & 2 & 4 & - & - & 1 & 8 & 10,13 \\
Análise Narrativa & 2 & - & 3 & - & - & - & 5 & 6,32 \\
Análise Bibliográfica & 1 & - & 1 & - & - & - & 2 & 2,54 \\
Grounded Theory & - & 1 & - & - & - & - & 1 & 1,27 \\
Não Identificado & 5 & 15 & 9 & 1 & - & 1 & 31 & 39,24 \\
\hline Total & $\mathbf{1 8}$ & $\mathbf{3 2}$ & $\mathbf{2 1}$ & $\mathbf{2}$ & $\mathbf{1}$ & $\mathbf{5}$ & $\mathbf{7 9}$ & $\mathbf{1 0 0}$ \\
\hline
\end{tabular}

Fonte: Elaborada pelos autores.

Um ponto a ser destacado é o fato de que, em muitos artigos analisados, os autores não explicitam qual técnica de análise foi utilizada, o que exigiu maior esforço em compreender o processo analítico operacionalizado. Ao final, apesar de ter sido possível classificar a maioria dos artigos quanto aos tipos de análise, percebeu-se que em apenas 21 deles ( $26,58 \%$ do total) os autores mencionaram, nos procedimentos metodológicos, a técnica de análise empregada.

Em um percentual representativo dos artigos $(39,24 \%)$ não foi possível identificar a técnica de análise. Ainda que muitos deles parecessem sugerir a adoção de alguma forma de AC, em virtude do emprego de algumas práticas, como recorrentes apresentações de - e menções a - segmentos de dados textuais coletados, essa classificação como AC não pareceu adequada. Na maioria dos casos prevalecia mais uma descrição dos dados levantados do que uma análise efetiva do material de pesquisa que alicerçasse argumentos e considerações dos autores.Os dados referentes a esse aspecto (tipos de análises realizadas), para o campo da Gestão Territorial, permitem problematizar em que medida os achados anteriormente apresentados estão associados às necessidades específicas da área e em que medida revelam apenas uma tendência em reproduzir modos convencionais de análise, ou, ainda, em privilegiar a apresentação descritiva dos dados de pesquisa, em detrimento de formas sistematizadas de tratamento destes.

\section{CRITÉRIOS DE QUALIDADE:}

\section{Margens Substanciais para Incrementos e Aperfeiçoamentos}

O último aspecto adotado, para a análise da produção científica aqui abordada, foi a da utilização de critérios de qualidade nos processos de pesquisa do campo da gestão territorial. Seis critérios de qualidade assumem relevo especial na pesquisa qualitativa, 
conforme discutem Paiva Júnior, Leão e Mello (2011), a partir da literatura especializada no assunto. Um primeiro deles é a triangulação, pelo qual se busca diminuir o nível de divergências e/ou contradições na análise de dados, seja por meio do emprego de múltiplas fontes desses, de análises comparadas de distintos pesquisadores, ou, ainda, de mais de um método ou teoria. Como segundo critério, os autores tratam da reflexividade, pela qual o pesquisador manteria, ao longo da pesquisa, um constante autoquestionamento sobre as interpretações que elabora, o que envolveria esforços de se voltar com frequência ao processo investigativo, a fim de aprimorar as análises realizadas. Por sua vez, o critério de construção do corpus de pesquisa consistiria em utilizar - e tornar explícitos - princípios operacionais para a seleção dos materiais a serem utilizados como fontes de dados na pesquisa, empregando o mecanismo de evidência de saturação dos dados com a finalidade de definir o tamanho adequado desse corpus. Um quarto critério seria a descrição densa, pela qual o contexto da investigação e os procedimentos adotados seriam expostos e suficientemente esmiuçados, de modo a garantir condições de compreensão e de reconstrução do estudo em outros cenários. Um quinto critério de qualidade consistiria no registro de surpresas, isto é, de elementos divergentes dos que poderiam sugerir alguma consideração teórica, algum método ou o conhecimento popular sobre o assunto estudado. Em sexto, é listada a validação comunicativa ou feedback dos informantes, processo pelo qual uma análise ou interpretação, na pesquisa, é submetida à apreciação de fontes, a fim de que o confronto com a perspectiva dessas possa aprimorar os resultados alcançados. Esses critérios, quando adotados - não necessariamente na totalidade do conjunto apresentado, mas conforme a natureza da investigação e do fenômeno em estudo - dotariam a pesquisa qualitativa de melhores condições para o alcance de resultados valiosos (PAIVA JÚNIOR; LEÃO; MELLO, 2011).

Para o conjunto analisado, de estudos sobre Gestão Territorial, verificou-se que o critério de qualidade mais presente foi o da triangulação (em $28,45 \%$ dos artigos), seguido pelo critério de descrição densa $(27,58 \%)$ e dos princípios de construção de corpus $(18,97 \%)$, como destacado na Tabela 6, na sequência. Os critérios reflexividade e registro de surpresas, ao seu turno, não foram explicitamente utilizados em nenhum dos trabalhos analisados. Ademais, cabe destacar que não foi possível identificar o emprego de quaisquer critérios de qualidade em um percentual representativo do material analisado $(24,14 \%)$.

Tabela 6 - Critérios de qualidade presentes nos estudos analisados

\begin{tabular}{|c|c|c|c|c|c|c|c|c|}
\hline $\begin{array}{l}\text { Critérios de } \\
\text { Qualidade }\end{array}$ & RAP & $0 \& S$ & CEBAPE.BR & ERA & Rausp & RAC & Total & $\%$ \\
\hline Triangulação & 12 & 10 & 7 & - & 3 & 1 & 33 & 28,45 \\
\hline Reflexividade & - & & - & - & - & - & - & 0 \\
\hline $\begin{array}{l}\text { Construção do } \\
\text { corpus }\end{array}$ & 11 & 3 & 8 & - & - & - & 22 & 18,97 \\
\hline Descrição densa & 14 & 7 & 7 & 1 & 2 & 1 & 32 & 27,58 \\
\hline $\begin{array}{l}\text { Registro de } \\
\text { surpresa }\end{array}$ & - & - & - & - & - & - & - & 0 \\
\hline $\begin{array}{l}\text { Validação por } \\
\text { informantes }\end{array}$ & - & 1 & - & - & - & - & 1 & 0,86 \\
\hline Não identificado & 11 & 7 & 8 & - & 1 & 1 & 28 & 24,14 \\
\hline Total & 48 & 28 & 30 & 1 & 6 & 3 & 116 & 100 \\
\hline
\end{tabular}

Fonte: Elaborada pelos autores. 
Como numa mesma investigação pode-se fazer uso de mais de um tipo de critério de qualidade (o que, inclusive, compreende um esforço desejável), a frequência absoluta acumulada, na Tabela 6, totaliza 116, um número maior do que o de artigos apreciados (79). Apesar disso, o significativo percentual de estudos nos quais nenhum critério dessa natureza foi evidenciado pode sinalizar que o campo possui considerável margem para um emprego mais intenso desses mecanismos, com vistas a promover o alcance de resultados de pesquisa cada vez mais valiosos.Perceba-se, também, que a adoção desses critérios não chega a constituir propriamente algo comum no campo, visto que nenhum deles, separadamente, foi verificado em mais que $28,45 \%$ do total sob análise. Finalmente, mesmo no que respeita à triangulação, a mais frequente das formas de ampliar a qualidade da pesquisa na área em estudo, sua quase totalidade é referente à triangulação de fontes, geralmente utilizada mais com o intuito de coletar dados complementares para a investigação do que com vistas à realização de confrontos entre dados distintos.

Cabe destacar que os critérios de qualidade aludidos aqui foram compreendidos a partir das especificidades do campo da tradição de pesquisa qualitativa (DEZIN; LINCOLN, 2006; LINCONL; GUBA, 2006), em vez de analisados à luz de perspectivas que tomam como parâmetros gerais aqueles critérios de amplo uso em pesquisas quantitativas. Embora uma discussão mais pormenorizada sobre esse tópico não esteja no escopo do presente trabalho, o debate sobre critérios de qualidade em Paiva Júnior, Leão \& Melo (2011) foi tomado como baliza para a análise realizada, visto que tais autores realizam substancial sistematização sobre o assunto, a partir da literatura a ele referente.

\section{CONSIDERAÇÕES FINAIS}

A análise aqui empreendida permite algumas considerações adicionais sobre o campo da pesquisa qualitativa em Gestão Territorial no Brasil, na área de Administração. Como visto, quando considerados apenas os trabalhos publicados em periódicos de melhor avaliação pelo Sistema Qualis/Capes, no decênio 2006-2015, esta produção concentra-se em três periódicos nacionais (RAP; O\&S; Cadernos EBAPE.BR), os quais representaram $89,87 \%$ do conjunto de trabalhos reunidos para a análise anteriormente realizada.

A predominância de perspectivas paradigmáticas construtivistas, neste conjunto de pesquisas, foi evidenciada no presente trabalho. Isso parece configurar uma característica favorável à natureza da temática do campo abordado, a qual envolve processos complexos, em variadas escalas e reunindo substancial diversidade de atores públicos e privados, com suas distintas lógicas de atuação, em dinâmicas contextuais específicas. Desse modo, há razões para crer que orientações epistemológicas como essa, centrada nas condições contextuais de produção dos saberes e de constituição da realidade, podem mostrar-se frutíferas à compreensão dos fenômenos abordados pelas pesquisas da área. Pode ser suscitada, todavia, uma reflexão mais aprofundada sobre esse alinhamento (entre peculiaridades do objeto de estudo e orientação paradigmática), indagando sobre outras possíveis razões para a prevalência construtivista ou, dito de outro modo, para a reduzida presença de trabalhos conduzidos mediante outras orientações paradigmáticas. 
No design das investigações realizadas, o campo da Gestão Territorial se caracteriza por uma forte adesão a propostas que utilizam aportes teóricos mais como auxílio analítico do que como fonte de modelos operacionais para a interpretação dos dados, prevalecendo os tipos que adotam as perspectivas da teoria geral e do modelo de construto. Visto que mesmo em pesquisas qualitativas é comum o recurso a modelos mais hipotético-dedutivos (com definição de conceitos e variáveis para a análise de dados, previamente à lida com o material de pesquisa), essas opções podem estar associadas à necessidade de privilegiar enfoques indutivos de investigação, ou pelo menos manter abertura para tal, por se tratar de um conjunto de estudos marcado pela baixa adesão à orientação positivista (a qual enfatizaria o método hipotético-dedutivo). Ainda, essa configuração pode ser devida às necessidades de produção de conhecimento da área na sociedade brasileira, caracterizada por uma elevada diversidade territorial, a qual implica múltiplos contextos a serem considerados nas análises.

Destacou-se, também, a concentração das estratégias de pesquisa em torno da tradição de estudos de caso. Quase sempre tais estudos assumem casos como formas de ilustrar ou explorar uma determinada questão de pesquisa, formulada inicialmente a partir da discussão temática de um específico tópico, posteriormente associado a uma determinada experiência a ser estudada. Em menor grau, contudo, aparecem também casos em que o interesse da pesquisa reside no contexto analisado em si e não numa questão de pesquisa prévia - os chamados casos intrínsecos, definidos por Stake (2005). Aqui, seria pertinente indagar o porquê da reduzida ou nula utilização de métodos vinculados às demais tradições de pesquisa qualitativa (etnografia, pesquisa narrativa, fenomenologia, grounded theory, por exemplo). Isto é, a ênfase no estudo de caso corresponde a uma característica pertinente aos contornos de investigação das temáticas abordadas ou haveria contribuições importantes de outras perspectivas que estariam sendo subestimadas ou mesmo ignoradas, no campo? Semelhantemente a Mariz et al. (2005), quando se referiram aos estudos organizacionais brasileiros, poder-se-ia refletir em que medida o estudo de caso, no campo da Gestão Territorial, é um recurso metodológico empregado como estratégia sistematizada e criteriosa de investigação e em que dimensão refletiria, de modo mais modesto, prioritariamente um esforço de delimitação do escopo das investigações empreendidas no campo.

Os trabalhos também concentram os dados utilizados em três fontes principais: documentos, entrevistas e observações dos pesquisadores, sendo que os dois primeiros, juntos, respondem por mais de $80 \%$ dos tipos dados aos quais o campo recorre. Certamente, esse ponto está relacionado com o reduzido emprego de tradições como a etnografia e a grounded theory, que podem sugerir mais enfaticamente uma maior diversidade na natureza dos dados, muito embora tal sugestão não esteja ausente em tradições como os estudos de caso.

Como em outros tópicos, é válido considerar possíveis motivações para a reduzida utilização de formas outras de investigação além do estudo de caso, o que seria oportuno também quanto ao fato de dados visuais e sons parecerem inexistentes no conjunto analisado. Também, ainda que corresponda a uma das três principais fontes de dados, a observação dos pesquisadores, vale notar, está presente em apenas 17,27\% dos estudos, reforçando a concentração nos dados oriundos de entrevistas e, sobretudo, documentais. O emprego intenso desses últimos, em especial, visto não serem 
predominantes na área de Administração como um todo, pode merecer uma discussão mais pormenorizada, o que envolveria refletir sobre as implicações da prevalência de dados secundários, cuja produção se dá fora do processo de desenvolvimento da pesquisa propriamente dita. Isto é, para as peculiaridades do campo da Gestão Territorial, esse seria um aspecto a favorecer (ou limitar) quais dimensões da produção de conhecimento? Ou quais precauções essa propriedade poderia ensejar, diante do intuito de se fortalecer a área de pesquisa em tela?

Em termos da forma pela qual são tratados os dados coletados pelos estudos sobre gestão territorial, a elevada concentração da Análise de Conteúdo revela uma tendência a seguir o campo da Administração como um todo. Deve-se considerar, porém, que, de modo condizente com a orientação qualitativa dos trabalhos analisados, o uso da AC muito raramente contempla a forma mais clássica desse tipo de análise. Isto é, prevalece uma análise mais descritiva, na qual os pesquisadores formulam categorias a partir de procedimentos que não incluem predominantemente o critério de recorrência estatística nos elementos textuais. Isso pode ajudar a compreender porque, mesmo com o uso da AC, a maioria dos trabalhos caracteriza-se como adotantes da perspectiva construtivista, visto que essa categorização, quase sempre, tem mais relação com os aspectos empíricos abordados nos trabalhos do que o uso de "grades de análise" antecipadamente formuladas a partir de referências apenas teóricas. Aqui, portanto, parece cair bem uma discussão sobre os distintos modos pelos quais a AC tem se apresentado nesses trabalhos e sobre a baixa frequência de outras formas de análise, possibilitando debater sobre caminhos que eventualmente se mostrem mais adequados ao campo, especialmente em razão do tipo de dados em uso e de outras questões que marcam a referida produção (a exemplo da abertura indutiva e da vinculação aos estudos de caso). Ainda nesse tópico, o fato de parcela substancial dos trabalhos $(39,24 \%)$ não esclarecer a forma de análise à qual os dados foram submetidos merece uma apreciação mais detida, podendo revelar, sobre a área, carências metodológicas ou a presença de procedimentos pouco usuais, ensejando aperfeiçoamentos que contornem esse ponto.

Debate semelhante pode ser aberto em relação aos procedimentos destinados a ampliar a qualidade da pesquisa qualitativa, observando-se os achados já apresentados sobre este ponto, para a área de gestão territorial. Deve-se considerar, nesse tópico, que parte importante da produção não apresenta claramente a incorporação de critérios de qualidade alinhados à tradição qualitativa, uma vez que mesmo a triangulação está ausente de muitos trabalhos - e, quando ocorre, trata-se apenas da triangulação de fontes ou adoção de dados complementares. Assim, mostra-se oportuno discutir como o debate metodológico sobre a adoção de critérios de qualidade em pesquisa qualitativa pode auxiliar o campo dos estudos em Gestão Territorial, suscitando questões diversas, tais como a eventual necessidade de expandir a utilização de critérios ainda pouco empregados (como a formação de corpus e o uso de descrição densa) ou mesmo daqueles que ainda se mostram ausentes dos trabalhos produzidos (como a validação por informantes ou o registro de surpresas). Aqui, novamente, sublinhe-se tratar-se da menção a critérios específicos à orientação qualitativa das referidas pesquisas, em vez de alusão ao emprego indiscriminado daqueles que têm uso corrente na pesquisa quantitativa. 
Por fim, registram-se aqui algumas perspectivas de aprimoramento e de ampliação da investigação ora apresentada, a fim de que se possa continuar o esforço iniciado e lançar novas luzes sobre o campo da pesquisa qualitativa nos estudos em Gestão Territorial. Nessa direção, quatro questões parecem centrais. Uma primeira consideração envolveria a produção de dados que propiciassem uma visão ainda mais aprofundada sobre os questionamentos lançados anteriormente, o que exigiria um retorno ao conjunto de trabalhos analisados, abordando neles outros pontos de análise; segundo, pode mostrar-se produtivo verificar eventuais associações, entre os pontos já tratados e elementos extrametodológicos a serem incorporados na estruturação da análise, tais como: as principais escolhas teóricas realizadas pelos autores, os tipos de processos e/ ou fenômenos investigados mais recorrentes nos estudos e os atores mais comumente envolvidos nesses processos/fenômenos; como terceiro ponto, proceder à expansão do escopo da produção investigada, contemplando outros estratos de avaliação no Sistema Qualis/Capes - especialmente os estratos B1 e B2 - nos quais há um número maior de periódicos nacionais e que podem reunir elevado número de estudos na temática pesquisada; e, como último ponto aqui elencado, uma ampliação do escopo de análise para a produção internacional e para além da área de Administração poderá, eventualmente, trazer à tona relevantes questões que não puderam ser aqui observadas.

\section{REFERÊNCIAS}

ABRAMOVAY, R. Para una teoría de los estudios territoriales. In: MANZANAL, M.; NIEMAN, G. (org.). Desarrollo rural: organizaciones, instituciones y territórios. Buenos Aires. Fund. Centro Integral Comunicación, Cultura y Sociedad - ICCUS, 2006.

ABRAMOVAY, R. O capital social dos territórios: repensando o desenvolvimento rural. Economia Aplicada, n. 2, v. IV, p. 379-397, abr./jun. 2000.

ANDION, C. Développement territorial durable en milieu rural, gouvernance et rôle des organisations non gouvernementales: I)État de Santa Catarina au Brésil. Mondes en Développement, v. 34, p. 85-100, 2006. ANDION, C. Análise de redes e desenvolvimento local sustentável. Revista de Administração Pública (Impresso), Rio de Janeiro, RJ, v. 37, p. 1.033-1.054, 2003.

BARDIN, L. Análise de conteúdo. Lisboa: Edições 70, 1977.

BOISIER, S. Em busca do esquivo desenvolvimento regional: entre a caixa-preta e o projeto político. Planejamento e Políticas Públicas, n. 13, jun. 1996.

BOISIER, S. La modernización del Estado: una mirada desde las regiones. Nueva Sociedad, n. 139, p. 3850, set./out. 1995.

BOURDIEU, P. A identidade e a representação. Elementos para uma reflexão crítica sobre a idéia de região. In: BOURDIEU, P. O poder simbólico. Rio de Janeiro: Bertrand Brasil, 2006.

BRANDÃO, C. A. Território e desenvolvimento: as múltiplas escalas entre o local e o global. Campinas, SP: Ed. da Unicamp, 2007a.

BRANDÃO, C. A. Territórios com classes sociais, conflitos, decisão e poder. In: ORTEGA, Antonio César; ALMEIDA FILHO, Niemeyer (org.). Desenvolvimento territorial, segurança alimentar e economia solidária. Campinas: Ed. Alínea, 2007b.

CASTELLS, M. A sociedade em rede. São Paulo: Paz e Terra, 2006.

CASTELLS, M. O poder da identidade. São Paulo: Paz e Terra, 1999.

CRESWELL, J. W. Projeto de pesquisa: métodos qualitativo, quantitativo e misto. 3. ed. Porto Alegre: Artmed, 2010.

CUNHA; A. M.; SIMÕES, R. F.; PAULA, J. A. Regionalização e história: uma contribuição introdutória ao debate teórico-metodológico. Belo Horizonte: UFMG; Cedeplar, 2005. (Texto para discussão, n. 260).

DALLABRIDA, V. R. Territory Planning and Management: the theory debate in Brazil and a prospect of practice according to theoretical contributions on territorial governance. Revista Brasileira de Gestão $e$ Desenvolvimento Regional, v. 11, p. 51-77, 2015. 
DALLABRIDA, V. R. Desenvolvimento e governança territorial: um ensaio preliminar sobre a necessidade da regulação no processo de gestão do desenvolvimento. Redes, v. 15, p. 165-186, 2010.

DEZIN, N. K.; LINCOLN, Y. S. (ed). O planejamento da pesquisa qualitativa: teorias e abordagens. Porto Alegre: Artmed, 2006.

DINIZ, C. C.; LEMOS, M. B. (org.). Economia e território. Belo Horizonte: EdUFMG, 2005.

EVANS, P. Além da "monocultura institucional": instituições, capacidades e o desenvolvimento deliberativo. Sociologias, Porto Alegre, ano 5, n. 9, 2003.

FISCHER, T. (org.). Gestão social e poderes locais: marcos teóricos e avaliação. Salvador, BA: Casa da Qualidade, 2002.

GODOI, C. K.; BANDEIRA-DE-MELLO, R. A. B. (org.). Pesquisa qualitativa em estudos organizacionais: paradigmas, estratégias e métodos. 1. ed. São Paulo. Saraiva, 2007.

GOULART, S. et al. Articulações em rede e acontecimentos no território: subsídios teóricos para formação de políticas públicas para o desenvolvimento. Cadernos EBAPE.BR, FGV, v. 8, p. 388-403, 2010.

HAESBAERT, R. O mito da desterritorialização: do "fim dos territórios» à multiterritorialidade. 7. ed. Rio de Janeiro: Bertrand Brasil, 2012.

LEÃO, A. L. M. S.; MELLO, S. B. C.; VIEIRA, R. S. G. O papel da teoria no método de pesquisa em Administração. Revista Organizações em Contexto, v. 5, n. 10, p. 1-16, 2009.

LINCOLN, Y. S.; GUBA, E. G. Controvérsias paradigmáticas, contradições e confluências emergentes. In: DEZIN, N. K; LINCOLN, Y. S. (Ed). O planejamento da pesquisa qualitativa: teorias e abordagens. Porto Alegre: Artmed, 2006.

MARIZ, L. A. et al. O reinado dos estudos de caso na Teoria das Organizações: imprecisões e alternativas. Cad. EBAPE.BR, vol. 3, n. 2, july 2005.

MULS, L. M. Desenvolvimento local, espaço e território: a importância da formação de redes entre organismos e instituições locais. Revista Economia, jan./abr. 2008.

OLIVEIRA, F. de. Aproximações ao enigma: o que quer dizer desenvolvimento local? São Paulo: Pólis; Programa Gestão Pública e Cidadania/EAESP/FGV, 2001. 40p.

PAIVA JR., F. G.; LEÃO, A. L. M. S.; MELLO, S. C. B. Validade e confiabilidade na pesquisa qualitativa. Revista de Ciências da Administração, v. 13, n. 31, p. 190-209, 2011.

RECKWITZ, A. Toward a theory of social practices: a development in culturalist theorizing. European Journal of Social Theory, v. 5, n. 2, p. 243-263, 2002.

SANTOS, M. Técnica, espaço, tempo: globalização e meio técnico-científico-informacional. 5 ed. São Paulo: Edusp, 2008.

TENÓRIO, F. G. (Re)visitando o conceito de Gestão Social. In: SILVA JUNIOR, J. T. et al. Gestão Social: práticas em debate, teorias em construção. Fortaleza: Imprensa Universitária. 2008.

TENÓRIO, F. G. Gestão social: uma perspectiva conceitual. Revista de Administração Pública, Rio de Janeiro, n. 5, vol. 32, 1998.

VIEIRA, M. M. F.; VIEIRA, E. F. Geoestratégia global: economia, poder e gestão de territórios. Rio de Janeiro: FGV, 2007. 